\title{
Homogenate Extraction of Polysaccharides from Pine Nut Meal: Optimization and Comparison with Other Extraction Methods by Characterizing Their Extracts
}

\author{
Hongwei Zhang, ${ }^{1,2}$ Yi Zhang, ${ }^{3}$ Yihong Bao $\left(\mathbb{D},{ }^{1}\right.$ Dianyu Yu $\left(\mathbb{D},{ }^{2}\right.$ and Lianzhou Jiang ${ }^{2}$ \\ ${ }^{1}$ School of Forestry, Northeast Forestry University, Harbin, Heilongjiang 150040, China \\ ${ }^{2}$ School of Food Science, Northeast Agricultural University, Harbin, Heilongjiang 150030, China \\ ${ }^{3}$ Department of Food Science \& Agricultural Chemistry, McGill University, Ste-Anne-de-Bellevue, \\ Montreal, Quebec, Canada H9X3V9 \\ Correspondence should be addressed to Yihong Bao; baoyihong@163.com
}

Received 27 January 2020; Revised 26 February 2020; Accepted 11 March 2020; Published 3 June 2020

Academic Editor: Barbara Speranza

Copyright (c) 2020 Hongwei Zhang et al. This is an open access article distributed under the Creative Commons Attribution License, which permits unrestricted use, distribution, and reproduction in any medium, provided the original work is properly cited.

\begin{abstract}
Homogenate extraction technology was applied to extract polysaccharides from pine nut (Pinus koraiensis) meal, a food waste from its oil processing. The first objective was to study the effects of liquid-solid ratio, homogenate extraction time, and temperature on the yield of pine nut meal polysaccharides (PNMP) using single-factor and Box-Behnken design. The optimal processing conditions were liquid-solid ratio of $43.23 \mathrm{~mL} / \mathrm{g}$ at $35^{\circ} \mathrm{C}$ for $2 \mathrm{~min} 50 \mathrm{sec}$ that produced PNMP yield of $11.7 \%$. Extraction factors interacted with each other significantly $(p<0.01)$. The second objective was to compare the homogenate extract with those produced using other methods including ultrasonic, microwave, and hot water extraction. Polysaccharides were separated using HPLC based on molecular weight (MW) and characterized with the polysaccharide and protein contents of each fraction. The homogenate PNMP had the most of small size $(<100 \mathrm{kDa})$ polysaccharides, and its glycoprotein fractions generally contained higher level of protein, as well as a high $\mathrm{ABTS}^{+}$scavenging activity observed by HPLC-UV-ABTS ${ }^{+}$assay. FTIR analysis was used to characterize the functional groups. Homogenate extraction is superior in producing PNMP compared with other common methods, and its PNMP extract has potential antioxidant benefit.
\end{abstract}

\section{Introduction}

Pinus koraiensis is a plant distributed in eastern Asia such as Korea and China; the produced pine nut, a major commercial nut products, is rich in nutrients including oils, fatty acids, proteins, polysaccharides, vitamins, and minerals with various beneficial effects [1-3]. Most research on pine nut aim to discover its oils, and thus the defatted pine nut meal (PNM) has been commonly considered as a by-product or agri-food waste from pine nut oil production. To add edible value into PNM, there have been a few research studies on the development of proteins and peptides from PNM, including novel peptides identified from PNM with antioxidant capacity and immunity enhancement ability $[4,5]$. Plant polysaccharides and oligosaccharides are natural constituents that can benefit human health in terms of antioxidant ability, anti-inflammation, immune-regulation, and hyperglycemia management $[6,7]$. Thus, PNM is used in this study to develop a new strategy for high value utilization of PNM.

Polysaccharides is a major component in pine nut. Recently, a polysaccharide complex with molecular weight (MW) of $23 \mathrm{kDa}$ containing carbohydrate, protein, and uronic acid, was separated from pine nut; its hepatoprotective effects against a few types of liver injury were also investigated in vitro [8]. Another $20.6 \mathrm{kDa}$ polysaccharides composed of arabinose, rhamnose, and glucose were purified from pine nut with various health benefits [9]. However, there have been little studies reported on producing crude polysaccharides from pine nut meal by different extraction methods. 
Commonly used extraction methods have many limitations in food industry, such as low yield, flavor and nutrients loss, energy consumption, and low efficiency. Homogenate extraction is to extract constituents from food materials in liquid via a combination of high-speed mechanical shearing, mixing, cutting, and smashing [10]. Homogenate extraction method can be applied at low temperatures for a short time when it is compared with other extraction methods; so, it is excellent in food industry to improve food quality, processing efficiency, consumption cost, and manufacturing operation. There have been several studies on the utilization of homogenate extraction for extracting bioactive food compounds such as alkaloids, pigments, and polysaccharides [10-13]. However, there is no report on polysaccharides extracted from pine nut meal using homogenate extraction method. Thus, one of the objectives in this study is to investigate the effects of homogenate extraction conditions such as liquid-solid ratio, extraction time, and temperature on the yield of pine nut meal polysaccharides (PNMP), followed by optimization study using response surface methodology (RSM).

The bioactivity of polysaccharides depend on several factors such as molecular weight, structure, protein level, type of linking, and sulfation degree [14]. In this study, chemical properties were determined including the total polysaccharide content, total protein content, and molecular weight of each polysaccharide fraction, in comparison with the bioactivity of PNMP extracts produced by other commonly-used extraction methods, that is, hot water extraction, microwave extraction, and ultrasonic extraction. Free radical $\mathrm{ABTS}^{+}$was used in a HPLC-UV-ABTS ${ }^{+}$assay system to characterize the potentials of PNMP extracts acting as natural antioxidants.

\section{Materials and Methods}

2.1. Pretreatment of Pine Nut Meal. Pine (Pinus koraiensis) nut meal was obtained from Hongtai pinecone Co., Ltd. (Heilongjiang, China). To get refined and defatted pine nut powder, the pine nut meal was degreased with petroleum ether, dried at $50^{\circ} \mathrm{C}$, and subsequently sieved through 60 mesh screen.

2.2. Chemicals. Ethanol (food grade) was purchased from GuangFu Group Co., Ltd. (China). All other chemicals and reagents used were of analytical grade. $\mathrm{NaCl}, \mathrm{KCl}, \mathrm{Na}_{2} \mathrm{HPO}_{4}$, $\mathrm{NaH}_{2} \mathrm{PO}_{4}, \mathrm{KH}_{2} \mathrm{PO}_{4}, \mathrm{MnO}_{2}, \mathrm{KBr}, \mathrm{H}_{2} \mathrm{SO}_{4}$, and ABTS $\left(2,2^{\prime}-\right.$ Azino-bis-(3-ethylbenzthiazoline-6-sulphonate) were purchased from sinopharm Chemical reagent Co., Ltd. (Shanghai, China). HPLC grade water was obtained from a MilliQ water purification system (Millipore, Bedford, New Hampshire, USA).

\subsection{Extraction of Pine Nut Meal Polysaccharides (PNMP) Using Different Methods}

2.3.1. Ultrasonic Extraction. The pretreated pine nut powder ( $2.5 \mathrm{~g})$ was soaked with distilled $\mathrm{H}_{2} \mathrm{O}(100 \mathrm{~mL})$ in a $250 \mathrm{~mL}$ flat bottom flask placed in the ultrasonic extraction device (XH-2008D, Beijing Xianghu Science and Technology Co., Ltd., Beijing, China) with power of $800 \mathrm{w}$ at $90^{\circ} \mathrm{C}$ for $30 \mathrm{~min}$ and a sequential extraction conducted at the same condition. After extraction, the mixture was centrifuged at $3000 \mathrm{~g}$ for $10 \mathrm{~min}$, and the supernatant was collected. The supernatant was first concentrated using rotary evaporation at $50^{\circ} \mathrm{C}$ and then precipitated by adding dehydrated ethanol to a final concentration of $80 \%(\mathrm{v} / \mathrm{v})$ and placed at $4^{\circ} \mathrm{C}$ for $24 \mathrm{~h}$. The mixture was centrifuged at $3000 \mathrm{~g}$ for $20 \mathrm{~min}$, and the sediment was collected and freeze-dried as crude PNMP powder. The crude PNMP yield (\%) was calculated using the following equation:

$$
\begin{aligned}
& \text { polysaccharides yield }(\%) \\
& =\frac{\text { weight of extracted polysaccharides }(g)}{\text { weight of pine nut meal }(g)} \times 100 \text {. }
\end{aligned}
$$

2.3.2. Microwave Extraction. The pretreated pine nut powder $(2.5 \mathrm{~g})$ was soaked with distilled $\mathrm{H}_{2} \mathrm{O}(100 \mathrm{~mL})$ in a $250 \mathrm{~mL}$ flat bottom flask placed in the microwave extraction device (XH-100A, Beijing Xianghu Science and Technology Co., Ltd., Beijing, China) with power of $800 \mathrm{w}$ at $90^{\circ} \mathrm{C}$ for $3 \mathrm{~min}$ and a sequential extraction conducted at the same condition. The process after extraction was the same as Section 2.3.1.

2.3.3. Hot Water Extraction. The pretreated pine nut powder $(2.5 \mathrm{~g})$ was soaked with distilled $\mathrm{H}_{2} \mathrm{O}(100 \mathrm{~mL})$ in a $250 \mathrm{~mL}$ flat bottom flask placed in the water bath at $90^{\circ} \mathrm{C}$ for $60 \mathrm{~min}$ and a sequential extraction conducted at the same condition. The process after extraction was the same as Section2.3.1.

2.3.4. Homogenate Extraction. The pretreated pine nut powder $(2.5 \mathrm{~g})$ was soaked with distilled $\mathrm{H}_{2} \mathrm{O}(100 \mathrm{~mL})$ in a $200 \mathrm{~mL}$ extraction tank using high-speed homogenizer (Supplementary Figure 1; T18, IKA Co., Ltd., Guangzhou, China) with $20,000 \mathrm{rpm}$ at $30^{\circ} \mathrm{C}$ for $2 \mathrm{~min}$. The process after extraction was the same as Section 2.3.1.

2.4. Response Surface Methodology (RSM) and Design. A three-factor Box-Behnken design (BBD) at three levels $(-1$, $0,+1)$ was carried out to study the homogenate extraction of PNMP. Based on the results of single-factor experiment, the levels of three factors were selected, that is, liquid-solid ratio $\left(X_{1}, \mathrm{~mL} / \mathrm{g}\right)$, extraction time $\left(X_{2}, \mathrm{~min}\right)$, and extraction temperature $\left(X_{3},{ }^{\circ} \mathrm{C}\right)$, and the response was PNMP yield (\%). The $\mathrm{BBD}$ design consisted of 17 experimental runs including 5 center points and 12 factorial points, as shown in Table 1 .

2.5. Determination of Total Polysaccharides and Protein. The total polysaccharides content of PNMP was determined by the phenol-sulfuric acid method using $\mathrm{D}^{\text {-glucose }}$ as the 
TABLE 1: The experimental data for the PNMP yield by homogenate extraction method using BBD design.

\begin{tabular}{|c|c|c|c|c|c|}
\hline \multirow[b]{2}{*}{ No. } & \multicolumn{3}{|c|}{ Independent variables } & \multicolumn{2}{|c|}{ Response } \\
\hline & $\begin{array}{l}X_{1}: \text { liquid-solid ratio } \\
(\mathrm{mL} / \mathrm{g})\end{array}$ & $\begin{array}{l}X_{2}: \text { extraction time } \\
(\min )\end{array}$ & $\begin{array}{c}X_{3} \text { : extraction temperature } \\
\left({ }^{\circ} \mathrm{C}\right)\end{array}$ & $\begin{array}{c}Y: \text { actual PNMP yield } \\
(\%)\end{array}$ & $\begin{array}{c}Y: \text { predicted PNMP yield } \\
(\%)\end{array}$ \\
\hline 1 & $-1(30)$ & $-1(2)$ & $0(35)$ & 9.6 & 9.7 \\
\hline 2 & $0(40)$ & $0(3)$ & $0(35)$ & 11.8 & 11.8 \\
\hline 3 & $1(50)$ & $0(3)$ & $-1(30)$ & 10.4 & 10.6 \\
\hline 4 & $0(40)$ & $0(3)$ & $0(35)$ & 11.9 & 11.8 \\
\hline 5 & $1(50)$ & $-1(2)$ & $0(35)$ & 11.3 & 11.1 \\
\hline 6 & $-1(30)$ & $0(3)$ & $1(40)$ & 10.0 & 9.8 \\
\hline 7 & $0(40)$ & $-1(2)$ & $-1(30)$ & 9.4 & 9.4 \\
\hline 8 & $0(40)$ & $0(3)$ & $0(35)$ & 11.8 & 11.8 \\
\hline 9 & $0(40)$ & $1(4)$ & $-1(30)$ & 10.0 & 9.9 \\
\hline 10 & $1(50)$ & $1(4)$ & $0(35)$ & 10.1 & 10.0 \\
\hline 11 & $-1(30)$ & $1(4)$ & $0(35)$ & 9.9 & 10.1 \\
\hline 12 & $1(50)$ & $0(3)$ & $1(40)$ & 9.7 & 9.8 \\
\hline 13 & $0(40)$ & $0(3)$ & $0(35)$ & 11.6 & 11.8 \\
\hline 14 & $0(40)$ & $0(3)$ & $0(35)$ & 11.7 & 11.8 \\
\hline 15 & $-1(30)$ & $0(3)$ & $-1(30)$ & 9.3 & 9.2 \\
\hline 16 & $0(40)$ & $1(4)$ & $1(40)$ & 9.0 & 9.0 \\
\hline 17 & $0(40)$ & $-1(2)$ & $1(40)$ & 10.1 & 10.2 \\
\hline
\end{tabular}

standard [15]. The protein content of PNMP was measured following the Bradford method using bovine serum albumin as the standard [16].

2.6. HPLC Analysis. A size exclusion chromatography analysis was performed on an Agilent 1100 Series HPLC System (Agilent Technologies, Pittsburg, USA) with G2000PW column $(7.5 \times 300 \mathrm{~mm}, 5 \mu \mathrm{m}$ sized particles $)$ (Tosoh Corporation, Tokyo, Japan). 0.1 M phosphate buffer ( $\mathrm{pH}$ 6.8) was used mobile phase. The UV detector at $280 \mathrm{~nm}$ and the RI detector are used in series. The column and refractive index (RI) detector temperature were at $35^{\circ} \mathrm{C}$. Flow rate was $1 \mathrm{~mL} / \mathrm{min}$. The injection volume was $100 \mu \mathrm{L}$ $(1 \mathrm{mg} / \mathrm{mL})$.

2.7. Online HPLC-UV-ABTS ${ }^{+}$Radical Scavenging Activity Analysis. The online HPLC-UV-ABTS ${ }^{+}$radical scavenging assay was based on HPLC and HPLC postcolumn analyses $[17,18]$. Briefly, the $\mathrm{ABTS}^{+}$solution was prepared by adding $2 \mathrm{~g} \mathrm{MnO}_{2}$ to $1 \mathrm{~L} 0.02 \mathrm{mM} \mathrm{ABTS}{ }^{+}$in PBS buffer $(\mathrm{pH} 7.4$, containing $8 \mathrm{~g} \mathrm{NaCl}, 1.4 \mathrm{~g} \mathrm{Na}_{2} \mathrm{HPO}_{4}, 0.15 \mathrm{~g} \mathrm{KCl}$, and $0.27 \mathrm{~g}$ $\mathrm{KH}_{2} \mathrm{PO}_{4}$ ). The solution was gently stirred for $10 \mathrm{~min}$ at room temperature and filtered $(0.2 \mu \mathrm{m}, 33 \mathrm{~mm}$, Nylon, PALL). The method of HPLC separation with UV detection was the same as Section 2.6. For the HPLC postcolumn analyses with a 2487 UV detector (Waters Corporation, Milford, MA, USA) to analyze online oxidation, the $\mathrm{ABTS}^{+}$solution was added at a flow rate of $0.8 \mathrm{~mL} / \mathrm{min}$, and the detection was performed at $414 \mathrm{~nm}$.

2.8. FTIR (Fourier Transform Infrared) Spectroscopic Analysis. FTIR spectroscopic measurements were conducted using a FTIR spectrometer (IRAffinity-1, Shimadzu Inc., Japan) according to the $\mathrm{KBr}$ pressed disc method. The spectrum was obtained between the wave number range of $4000-400 \mathrm{~cm}^{-1}$ with a resolution of $1 \mathrm{~cm}^{-1}$.

2.9. Statistical Analyses. All the experiments were performed with triplicates, and data was analyzed using the general linear model's procedure for variance (ANOVA) of the Statistix software 8.1 (Analytical Software, Tallahassee, FL, USA). LSD all-pairwise multiple comparisons was performed to identify significant differences $(p<0.05)$ between individual means. The RSM data was analyzed using the Design-Expert software (version 8.0 trial, Stat-Ease, Inc., Minneapolis, USA).

\section{Results and Discussion}

3.1. Single Factor Experiments on the Homogenate Extraction of PNMP. To study the polysaccharide yield (\%) of the PNMP extracts produced using homogenate extraction method, the effects of liquid-solid ratio $(\mathrm{mL} / \mathrm{g})$, extraction time (min) and extraction temperature $\left({ }^{\circ} \mathrm{C}\right)$ were investigated at first, as shown in Figure 1.

Regarding the effect of liquid-solid ratio, homogenate extraction was performed at liquid-solid ratio of 10, 20, 30, 40,50 , and $60 \mathrm{~mL} / \mathrm{g}$, respectively, at extraction temperature of $20^{\circ} \mathrm{C}$ for $2 \mathrm{~min}$ with shear speed of $20,000 \mathrm{rpm}$. As shown in Figure 1(a), the polysaccharide yield increased significantly when the liquid-solid ration increased from 10 to $40 \mathrm{~mL} / \mathrm{g}(p<0.05)$ and obtained the maximum value of $10.40 \%$ at $60 \mathrm{~mL} / \mathrm{g}$. It can be explained that a liquid-solid ratio $>40 \mathrm{~mL} / \mathrm{g}$ favored the diffusion of extraction liquid into the pine nut meal powder cells for a better dissolution of polysaccharides [19]. Previous reports showed similar trend that the polysaccharides from extracts eventually showed a stable level up to a certain level of liquid-solid ratio [20, 21]. Thus, liquid-solid ratio of 30,40 , and $50 \mathrm{~mL} / \mathrm{g}$ was used for the subsequent RSM experiment. 


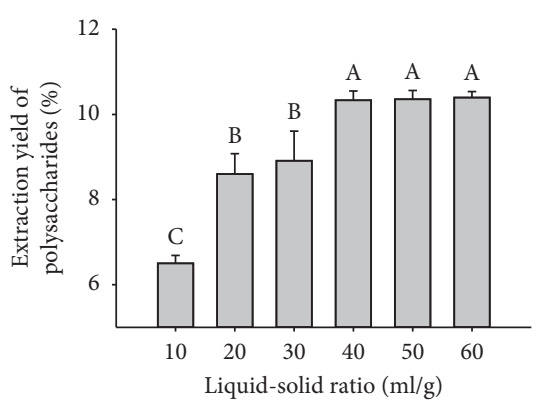

(a)

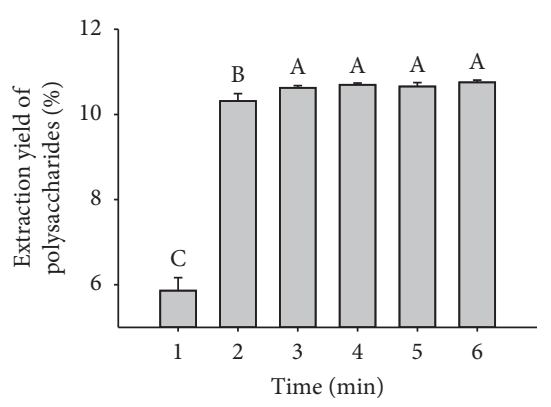

(b)

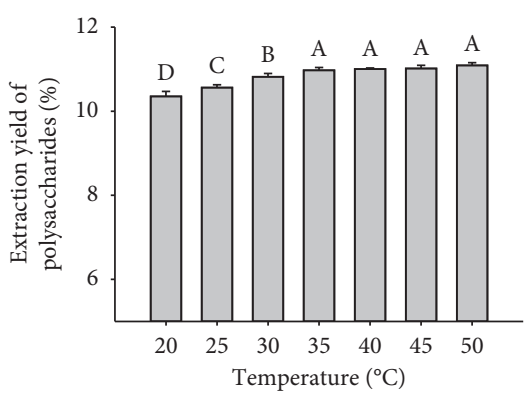

(c)

Figure 1: The effects of (a) liquid-solid ratio ( $\mathrm{mL} / \mathrm{g})$, (b) extraction time (min), and (c) extraction temperature $\left({ }^{\circ} \mathrm{C}\right)$ on the polysaccharide yield in the PNMP extracts using homogenate extraction method. The different letters $(\mathrm{A}, \mathrm{B}, \mathrm{C}$, and $\mathrm{D})$ in each graph indicate significant difference $(p<0.05)$.

TABLE 2: Statistical summary of the surface response analysis.

\begin{tabular}{lcccc}
\hline Source & Sum of squares & Mean square & $F$ value & $p$ value \\
\hline Model & 14.8 & 1.64 & 52.78 & $<0.0001^{* *}$ \\
$X_{1}$ & 0.81 & 0.81 & 25.88 & $0.0014^{* *}$ \\
$X_{2}$ & 0.21 & 0.21 & 6.88 & $0.0342^{*}$ \\
$X_{3}$ & 0.011 & 0.011 & 0.34 & 0.5796 \\
$X_{1}^{2}$ & 1.53 & 1.53 & 49.00 & $0.0002^{* *}$ \\
$X_{2}^{2}$ & 2.9 & 2.9 & 93.02 & $<0.0001^{* *}$ \\
$X_{3}^{2}$ & 6.42 & 6.42 & 205.98 & $<0.0001^{* *}$ \\
$X_{1} X_{2}$ & 0.53 & 0.53 & 17.10 & $0.0044^{* *}$ \\
$X_{1} X_{3}$ & 0.53 & 0.53 & 17.10 & $0.0044^{* *}$ \\
$X_{2} X_{3}$ & 0.73 & 0.73 & 23.46 & $0.0019^{* *}$ \\
Residual & 0.22 & 0.031 & & \\
Lack of fit & 0.16 & 0.054 & 3.74 & 0.1173 \\
Pure error & 0.057 & 0.014 & & \\
$R^{2}$ & 0.9855 & & & \\
$R^{2}$-adj & 0.9668 & & & \\
C.V.(\%) & 1.69 & & & \\
\hline
\end{tabular}

Note. $X_{1}$ is liquid-solid ratio, $X_{2}$ is extraction temperature, and $X_{3}$ is and extraction time. ${ }^{*}$ Significant coefficient $(p<0.05) .{ }^{* *}$ High significant coefficient $(p<0.01)$.

Regarding the effect of extraction time, homogenate extraction was performed for $1,2,3,4$, and 5 min, respectively, at liquid-solid ratio of $40 \mathrm{~mL} / \mathrm{g}$ and $20^{\circ} \mathrm{C}$ with shear speed of $20,000 \mathrm{rpm}$. As shown in Figure 1(b), there was a dramatically improvement in the polysaccharides yield when extraction time increased from 1 to $2 \mathrm{~min}(p<0.05)$ and became stable after $3 \mathrm{~min}(p>0.05)$. Thus, extraction time of 2,3 , and $4 \mathrm{~min}$ was chosen for the subsequent RSM experiment.

Regarding the effect of extraction temperature, homogenate extraction was performed at 20, 25, 30, 35, 40, 45, and $50^{\circ} \mathrm{C}$, respectively, at liquid-solid ratio of $40 \mathrm{~mL} / \mathrm{g}$ for $2 \mathrm{~min}$ with shear speed of 20,000 rpm. The polysaccharide yields of PNMP gradually enhanced with increasing of temperature from 20 to $35^{\circ} \mathrm{C}(p<0.05)$, as shown in Figure 1(c). The yields were stable at $11 \%$ when extraction temperature was above $35^{\circ} \mathrm{C}(p>0.05)$. Thus, extraction temperature of 30,35 , and $40^{\circ} \mathrm{C}$ was selected for the subsequent RSM experiment.

\subsection{The RSM Model of PNMP Yield by Homogenate} Extraction. The PNMP yields of the extracts produced by homogenate extraction method under various conditions designed by BBD are presented in Table 1 . The difference in the response value indicated that homogenate extraction factors including liquid-solid ratio $\left(X_{1}, \mathrm{~mL} / \mathrm{g}\right)$, extraction time $\left(X_{2}, \min \right)$, and extraction temperature $\left(X_{3},{ }^{\circ} \mathrm{C}\right)$ influenced the PNMP yield.

Response surface analysis data for the response in Table 2 shows that the quadratic (second-order) polynomial model was significant ( $p$ value $<0.0001, F$ value $=52.78$ ). For the fitted model, as shown in equation (2), the $p$ values $\leq 0.01^{* *}$ indicated that the linear effect $X_{1}$, quadratic effects $X_{1}^{2}, X_{2}^{2}, X_{3}^{2}$, and interaction terms $X_{1} X_{2}, X_{1} X_{3}, X_{2} X_{3}$ were highly significant, and the linear effect $X_{2}\left(p\right.$ value $\left.\leq 0.05^{*}\right)$ was significant. $X_{3}$ with $p$ value of 0.5796 suggested that the extraction time was not a significant effect. The lack of fit ( $p=0.1173$ ) was not significant indicating that the model fitted the experimental data well. $R^{2}$ and adjusted $R^{2}$ were 0.9855 and 0.9668 , respectively, which is desirable.

$$
\begin{aligned}
Y= & 11.68+0.32 X_{1}-0.16 X_{2}-0.036 X_{3}-0.36 X_{1} X_{2} \\
& -0.36 X_{1} X_{3}-0.43 X_{2} X_{3}-0.6 X_{1}^{2}-0.83 X_{2}^{2}-1.23 X_{3}^{2} .
\end{aligned}
$$

\subsection{The Effects of Homogenate Extraction Conditions on} PNMP Yield. The contour plots of the model in Figure 2 show the interaction relationship of the studied extraction factors as a function of PNMP yield. All three contour plots are elliptical in shape, suggesting strong interactions between two extractions factors [22] that could also be indicated from Table 2. It can be seen that the effect of liquidsolid ratio $\left(X_{1}\right)$ has the densest contour lines along its homologous axis, followed by effect of extraction time $\left(X_{2}\right)$, implying that $X_{1}$ and $X_{2}$ were the two factors that would mostly influence the PNMP yield, which could also be suggested from data in Table 2. As shown in Figure 2(a), an increase of liquid-solid ratio ( $X_{1}$, from 30 to $45 \mathrm{~mL} / \mathrm{g}$ ) combined with an increase of extraction time $\left(X_{2}\right.$, from 2 to $3 \mathrm{~min}$ ) caused an increase in PNMP yield. Generally, higher volume of extraction liquid combined with higher temperature to extract polysaccharides favors an easier dissolving and faster diffusion of compounds from pine nut meat powder. However, there might be loss and damage of 


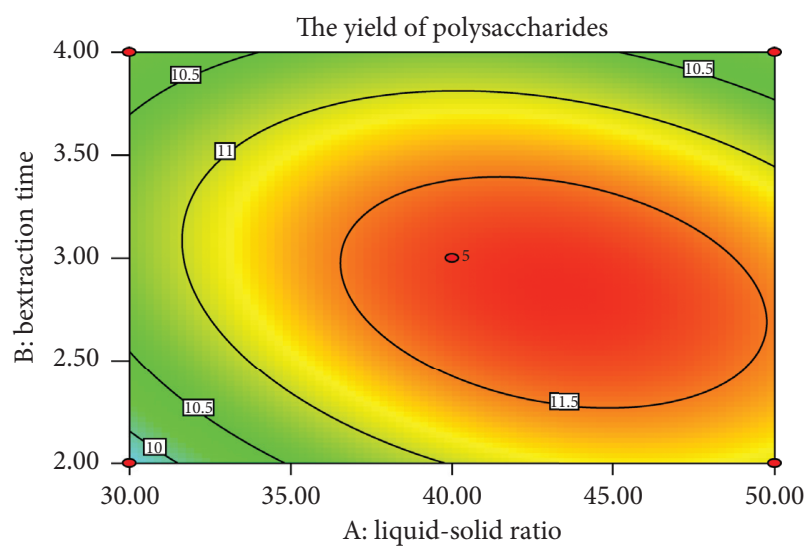

(a)

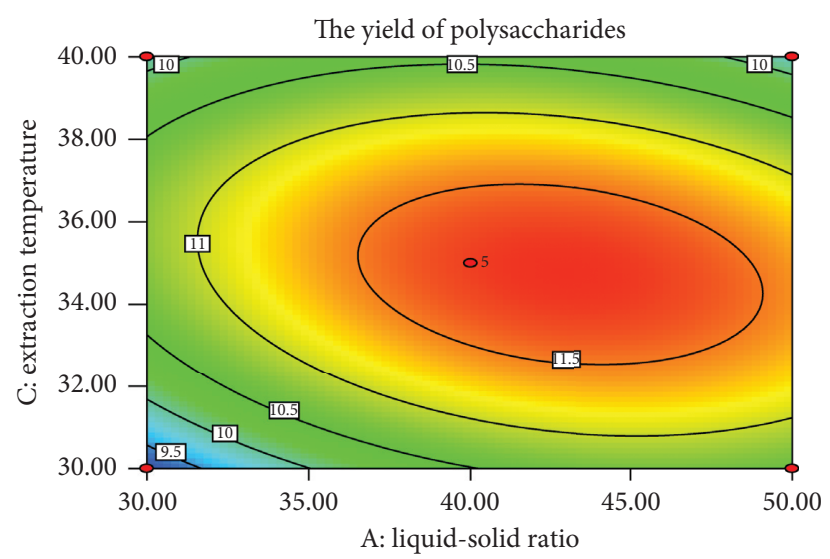

(b)

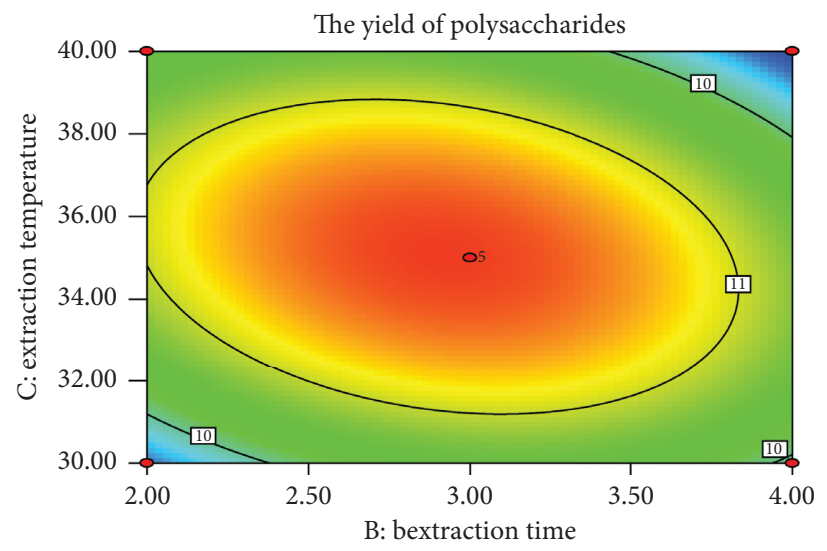

(c)

Figure 2: Contour plots. (a) PNMP yield (\%) using homogenate extraction method as a function of liquid-solid ratio $\left(X_{1}\right)$ and extraction time $\left(X_{2}\right)$; (b) PNMP yield (\%) using homogenate extraction method as a function of liquid-solid ratio $\left(X_{1}\right)$ and extraction temperature $\left(X_{3}\right)$; (c) PNMP yield (\%) using homogenate extraction method as a function of extraction time $\left(X_{2}\right)$ and extraction temperature $\left(X_{3}\right)$.

extracted polysaccharides if the liquid volume and temperature were too high. Figure 2(b) showed the effect of liquid-solid ratio $\left(X_{1}\right)$ and extraction temperature $\left(X_{3}\right)$ on the PNMP yield. The highest PNMP yield was observed at liquid-solid ratio of $43 \mathrm{~mL} / \mathrm{g}$ at $35^{\circ} \mathrm{C}$. Figure 2(c) showed the effect of extraction time $\left(X_{2}\right)$ and extraction temperature $\left(X_{3}\right)$ on the PNMP yield. Excessive high temperature above $35^{\circ} \mathrm{C}$ and longtime above 3 min negatively influenced the PNMP yield, which might be due to the degradation of polysaccharides.

3.4. Optimum Conditions and Validation. The optimum conditions predicted for the polysaccharides extraction from pine nut meal were as follows: liquid-solid ratio of $43.23 \mathrm{~mL} /$ $\mathrm{g}$ at extraction temperature of $35^{\circ} \mathrm{C}$ for an extraction time of 2 min $50 \mathrm{sec}$. The maximum predicted PNMP yield was $11.75 \%$ under the optimal conditions. To validate the prediction, PNMP was extracted using the above conditions and the experimental result was $11.68 \pm 0.14 \%$, showing no significant difference from the predicted value $(p>0.05)$. The optimized PNMP was used for subsequent analysis to compare the homogenate extraction method with other commonly used extraction methods.
3.5. Comparision of Homogenate Extraction Method with Others. To compare the efficacy of novel homogenate extraction method with other commonly used extraction methods such as ultrasonic extraction, microwave extraction, and hot water extraction, several assays were conducted on their polysaccharide extracts using methods described in Subsections 2.5-2.8. The PNMP were produced by other methods as indicated in Sections 2.3.1-2.3.3. The PNMP produced using homogenate extraction method was based on optimum conditions in Subsection 3.4.

3.5.1. Polysaccharides Yield and Total Polysaccharides and Protein Contents. Table 3 shows the polysaccharides yield (\%), total polysaccharides content (\%), and total protein content of the PNMP extract produced using various methods. The polysaccharides yield from homogenate extraction method was $11.7 \pm 0.1 \%$, significantly higher than other methods $(p<0.05)$. Similarly, homogenate extraction method produced the highest total polysaccharides content $(43.6 \pm 2.1 \%)$ and the lowest total protein content $(41.7 \pm 1.2 \%)$ of PNMP extract, but it was not significantly different from ultrasonic extraction method with corresponding values of $42.9 \pm 1.8 \%$ and $40.5 \pm 1.1 \%$, respectively 
TABLE 3: The polysaccharides yield, total polysaccharides, and protein contents of the PNMP extract produced by three convention methods and optimized homogenate extraction method.

\begin{tabular}{lcccc}
\hline & Ultrasonic extraction & Microwave extraction & Hot water extraction & Homogenate extraction \\
\hline Polysaccharides yield (\%) & $10.6 \pm 0.2^{\mathrm{b}}$ & $7.7 \pm 0.2^{\mathrm{c}}$ & $6.9 \pm 0.1^{\mathrm{d}}$ & $11.7 \pm 0.1^{\mathrm{a}}$ \\
Total polysaccharides content (\%) & $42.9 \pm 1.8^{\mathrm{a}}$ & $38.7 \pm 1.1^{\mathrm{b}}$ & $32.7 \pm 1.2^{\mathrm{c}}$ & $43.6 \pm 2.1^{\mathrm{a}}$ \\
Total protein content (\%) & $40.5 \pm 1.1^{\mathrm{b}}$ & $45.9 \pm 1.6^{\mathrm{a}}$ & $44.8 \pm 2.0^{\mathrm{a}}$ & $41.7 \pm 1.2^{\mathrm{b}}$ \\
\hline
\end{tabular}

Note. Different letters in the same row indicate significant difference $(p<0.05)$.

$(p>0.05)$. However, in terms of processing efficiency, homogenate extraction conducted for 6 min was much shorter than the ultrasonic extraction for $60 \mathrm{~min}$. The above results show that homogenate extraction method is superior to other extraction methods to produce high-level polysaccharides in the extracts. Based on it, a combined method using ultrasonic and homogenate could be investigated on the PNMP extraction in the future.

3.5.2. HPLC Analyses. The size exclusion chromatographic analyses on a HPLC system equipped with RI and UV $280 \mathrm{~nm}$ detection for polysaccharides and protein in PNMP extracts, shown as blue and black dashed lines, respectively, were shown in Figure 3. A previous study has discussed that the soluble polysaccharide-protein complex possibly existed and was responsible for the high stability and emulsifying activity of glutelin in pine nut [23]. The peaks appearing in the elution profile from HPLC analyses suggest that the PNMP extract consisted of glycoproteins. It can be seen that there were three major peaks presented at 5-7 min, 9-10 min, and 11-12 min during the elution for extracts produced by all the four extraction methods; however, the numbers of peaks and the area of each peak varied among them, which suggested that different extraction method contributed to difference in polysaccharides/glycoprotein components as well as the amount of each component in PNMP extract. In general, the overall peaks patterns seemed to be similar for microwaves and hot water extraction methods (Figures 3(b) and 3(c)). PNMP extract from ultrasonic method had more peaks especially in fractions eluted after $12 \mathrm{~min}$ (Figure 3(a)). Homogenate extraction method generated larger peaks (Figure $3(\mathrm{~d})$ ) compared with other methods at $10 \mathrm{~min}$.

Each of the peak fractions was collected and measured using phenol-sulfuric acid method and Bradford method described in Section 2.5 to determine the total polysaccharide and protein contents, shown as blue and black columns, respectively, in the bar graph below each elution profile in Figure 3. Microwave extraction method and hot water extraction methods led to low content of polysaccharide/protein in the PNMP extracts (Figures 3(b) and $3(c))$, especially the hot water extraction, which had the worst effect in producing PNMP enriched product. Generally, ultrasonic extraction method could generate glycoprotein fractions containing higher portion of polysaccharides (Figure 3(a)); in contrast, homogenate extraction method produced fractions with higher amount of protein (Figure 3(d)). For example, the fraction eluted at $8-9 \mathrm{~min}$ from ultrasonic extract contained $35 \mu \mathrm{g} / \mathrm{mL}$ polysaccharides and $17 \mu \mathrm{g} / \mathrm{mL}$ protein (Figure 3(a)), but the corresponding elution fraction from homogenate extract contained $15 \mu \mathrm{g} / \mathrm{mL}$ polysaccharides and $36 \mu \mathrm{g} / \mathrm{mL}$ protein (Figure 2). The reason could be that the long-time hightemperature ultrasonic treatment enhanced the hydrolysis and degradation of the biopolymers $[24,25]$ in the PNMP extracts to a larger extent than homogenate extraction treatment.

Based on the peaks detected using RI detector and the standard curve, the exact molecular weight (MW) of each peak was determined. Figure 4 shows the MW distribution of polysaccharides in the PNMP extracts produced by various extraction methods. Homogenate extraction method produced the highest percentage of low MW polysaccharides component, that is, $>90 \%$ of polysaccharides with $\mathrm{MW}<100 \mathrm{kDa}$. It could be caused by the no thermal polymerization on the PNMP caused by homogenate treatment. Moreover, homogenate extraction produced the most of medium MW polysaccharides $(20-100 \mathrm{kDa})$ but the least of low MW polysaccharides $(<20 \mathrm{kDa})$. A similar $\mathrm{MW}$ distribution pattern was found for the PNMP extract from ultrasonic method.

3.5.3. HPLC-UV-ABTS ${ }^{+}$Analyses. An online HPLC-UV-ABTS ${ }^{+}$system was used, which was detected at UV $414 \mathrm{~nm}$, shown as the red dashed lines in Figure 3, and the corresponding $\mathrm{ABTS}^{+}$scavenging activity of each peak was presented as red columns in the bar graph below each elution profile. Online HPLC-UV-ABTS ${ }^{+}$based assay is sensitive and relatively simple [17] and has been successfully used in the rapid detection of antioxidants such as flavonoids in azalea flowers [26] and phenolic antioxidants in Salsola komarovii [27]. Regarding the UV $414 \mathrm{~nm}$ plots in Figure 3, the larger the negative peak area, the higher th antioxidant activity of the eluted components. In this case, the peak eluted at 6-7 min had the highest $\mathrm{ABTS}^{+}$scavenging activity for ultrasonic, microwave, and hot water extracts (Figures 3(a)-3(c)); however, there was another peak found with higher antioxidant activity for homogenate extract (Figure 3(d)). Thus, the homogenate extraction method produced the most antioxidant PNMP extract, especially the eluted peaks at $\sim 9 \mathrm{~min}$ and $\sim 10 \mathrm{~min}$ with $\mathrm{ABTS}^{+}$scavenging activity of $18 \%$ and $32 \%$, respectively, while the conventional hot water extraction produced the least. By combining with the HPLC assay and Figure 4, it can be verified that the large amount of medium MW polysaccharides and glycoprotein components in the PNMP extract produced by homogenate extraction was responsible for its high antioxidant activity. 

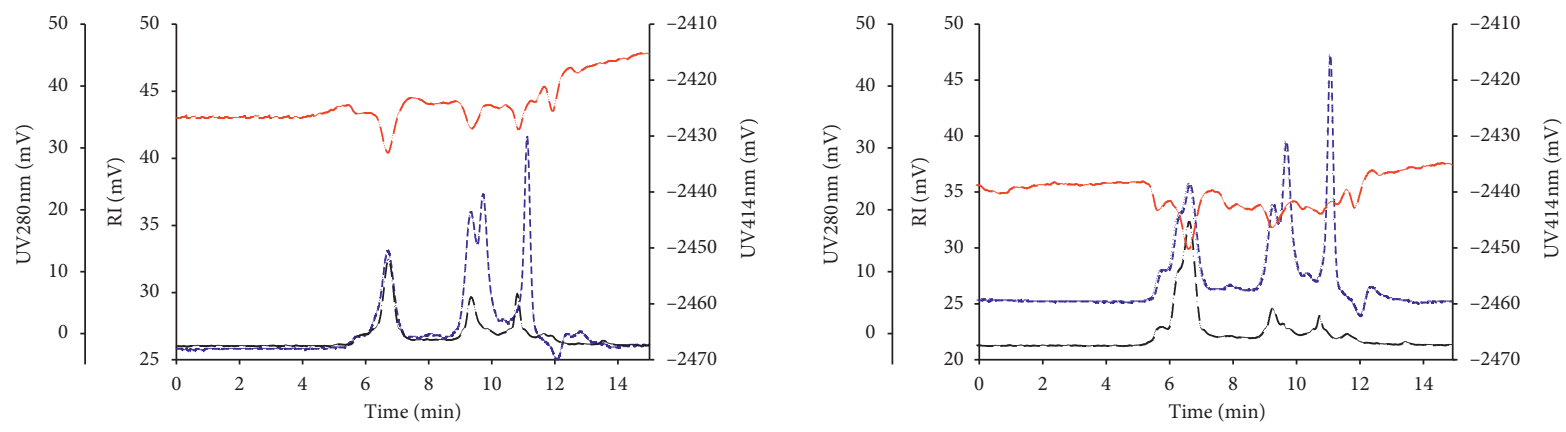

- RI

. UV280nm

- UV414nm

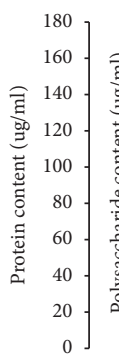

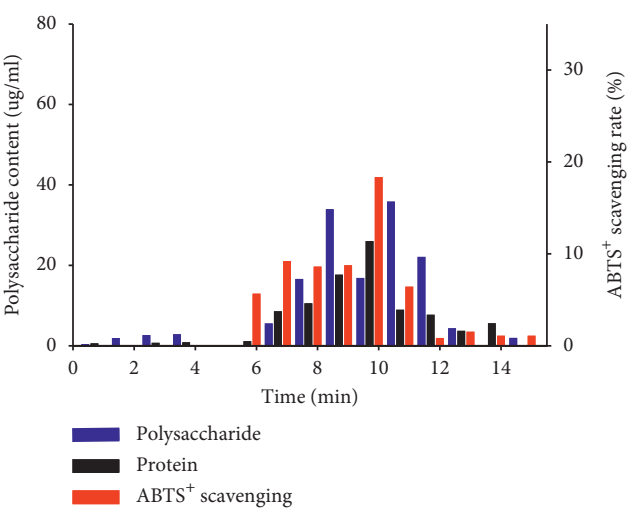

(a)

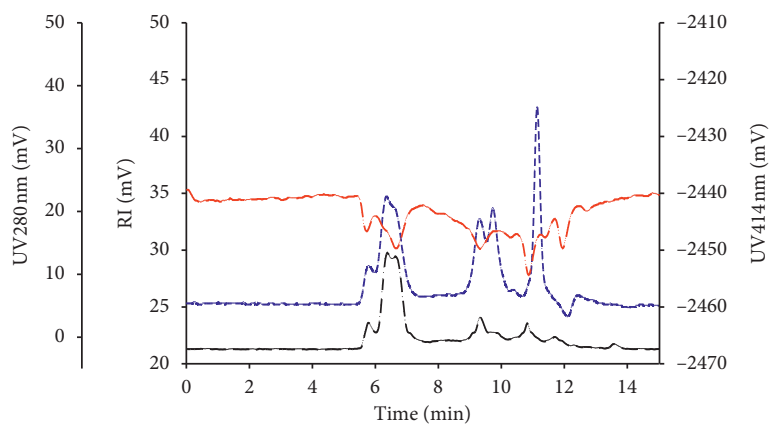

- UV280nm

. UV414nm

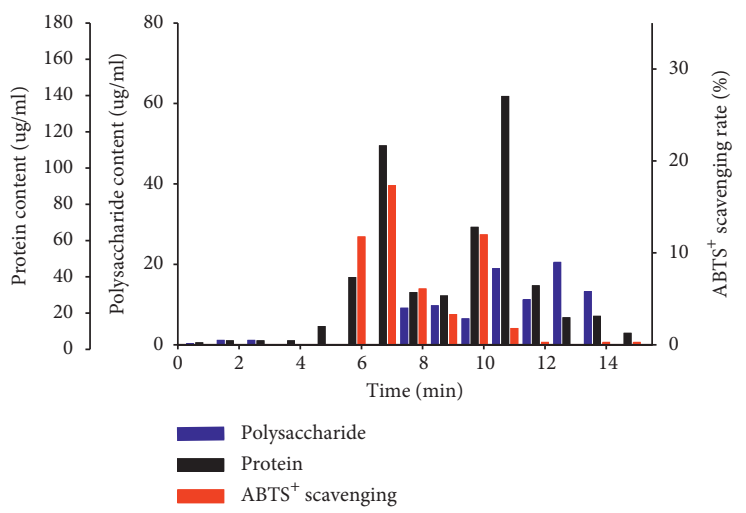

(b)

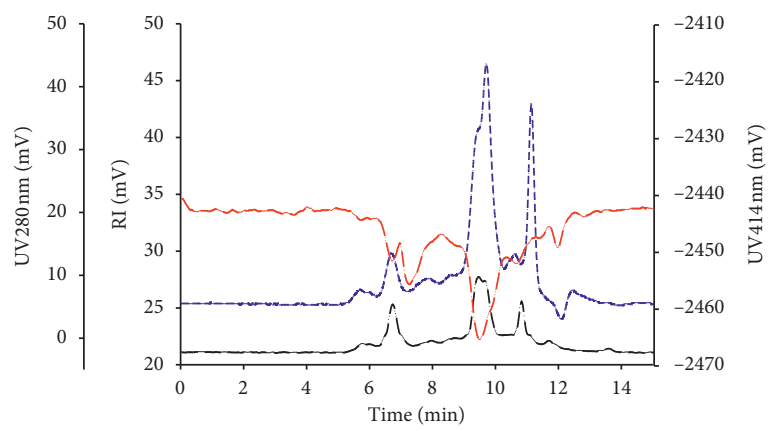

- RI

- UV280nm

- UV414nm

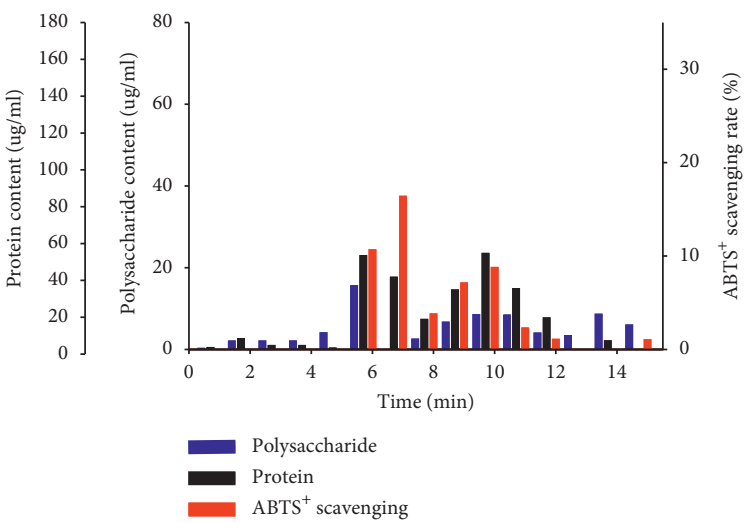

- RI

. UV280nm

- UV414nm

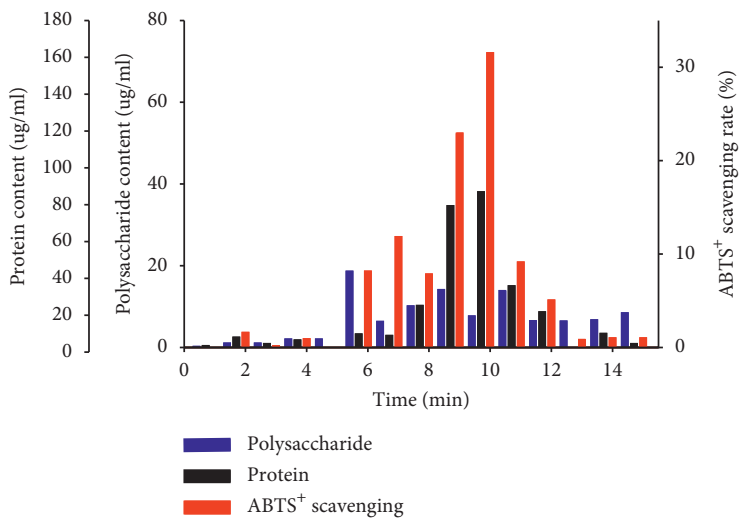

(c)

(d)

FIGURE 3: Elution profile HPLC and online HPLC-UV-ABTS + chromatography, respectively, on the PNMP extract produced by: (a) ultrasonic extraction, (b) microwave extraction, (c) hot water extraction, and (d) homogenate extraction. 


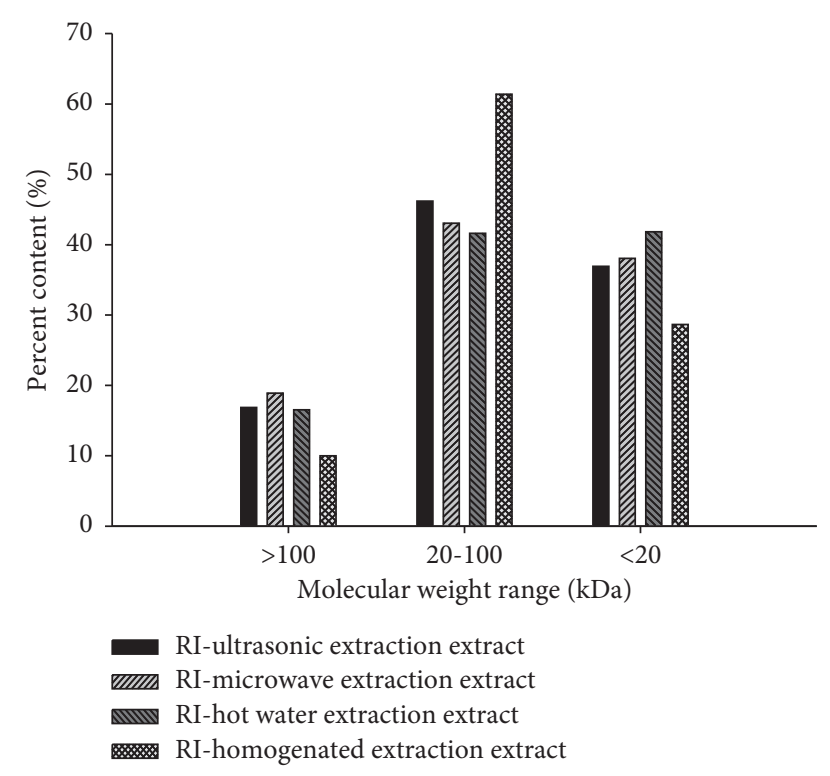

FIgURE 4: The molecular weight range of the polysaccharides in PNMP extracts produced by three other extraction methods and homogenate extraction method.

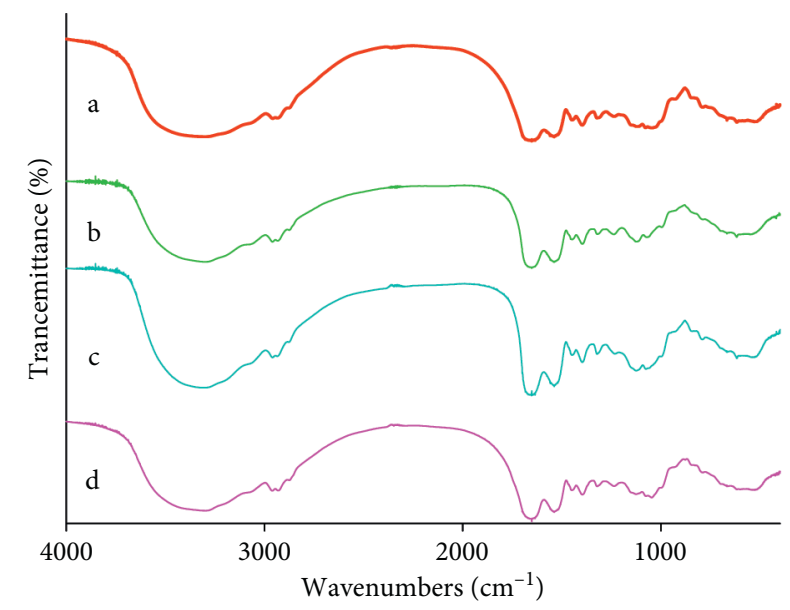

FIgUre 5: The FTIR spectra of PNMP extracts from (a) ultrasonic extraction method, (b) microwave extraction method, (c) hot water extraction method, and (d) homogenate extraction method.

3.5.4. FTIR Analyses. Figure 5 is the FTIR spectra of the PNMP extracts using various extraction methods. As reported previously, the wide absorption bands at $3430 \mathrm{~cm}^{-1}$ resulted from the hydroxyl stretching vibrations of the polysaccharides or the possibly existing bound water in the PNMP extracts, and the weak absorption bands at $2935 \mathrm{~cm}^{-1}$ were originated from $\mathrm{C}-\mathrm{H}$ stretching of methyl group. The intense peaks at approximately $1625 \mathrm{~cm}^{-1}$ were attributed to $\mathrm{C}=\mathrm{O}$ asymmetric stretching vibration in a carbonyl group or the possibly existing bound water in the PNMP extracts, and the absorbance at $1430 \mathrm{~cm}^{-1}$ was associated with the $\mathrm{C}-\mathrm{H}$ bending or stretching frequencies $[28,29]$. Similar FTIR spectra were found for polysaccharides from pine cones [30]. The shape of the amide I band located at $1600-1700 \mathrm{~cm}^{-1}$ is used to determine the secondary structure of protein
$[31,32]$, which could also be observed in Figure 5. The four spectra were in similar shape, which suggested all the extracts contained similar components, that is, polysaccharides/protein or glycoprotein.

\section{Conclusions}

Homogenate extraction technology is revealed to be an efficient, simple, and fast processing method to produce polysaccharides extract from pine nut meal. This present study provides a suitable approach to add value to the underutilized food waste-pine nut meal. Optimization study suggested the optimal conditions to obtain the maximum polysaccharide yield. For homogenate extraction, the relatively low temperature and short extraction time probably contributed to the good quality of the extracted polysaccharides, in terms of the protein content, molecular weight distribution of polysaccharides, and free radical scavenging activity. In comparison with other commonly used extraction methods such as ultrasonic, microwave, and hot water, homogenate extraction is superior. The polysaccharides extracted from pine nut meal showed potential health beneficial effects.

\section{Data Availability}

The data used to support the findings of this study are included within the article.

\section{Conflicts of Interest}

The authors declare that they have no conflicts of interest.

\section{Acknowledgments}

This research was funded by Heilongiiang Provincial Natural Science Foundation of China (Grant no. ZD2019C002) and the National Key Research and Development Program of China (Grant no. 2018YFD0401101).

\section{Supplementary Materials}

Supplementary Figure 1: the draft of the device used for homogenate extraction. (Supplementary Materials)

\section{References}

[1] N. H. Le, S. Shin, T. H. Tu et al., "Diet enriched with Korean pine nut oil improves mitochondrial oxidative metabolism in skeletal muscle and brown adipose tissue in diet-induced obesity," Journal of Agricultural and Food Chemistry, vol. 60, no. 48, pp. 11935-11941, 2012.

[2] L. Cai, L. Xiao, C. Liu, and T. Ying, "Functional properties and bioactivities of pine nut (Pinus gerardiana) protein isolates and its enzymatic hydrolysates," Food and Bioprocess Technology, vol. 6, no. 8, pp. 2109-2117, 2013.

[3] W. J. Pasman, J. Heimerikx, C. M. Rubingh et al., "The effect of Korean pine nut oil on in vitro CCK release, on appetite sensations and on gut hormones in post-menopausal overweight women," Lipids in Health and Disease, vol. 7, no. 1, p. 10, 2008. 
[4] R. Yang, X. Li, S. Lin, Z. Zhang, and F. Chen, "Identification of novel peptides from 3 to $10 \mathrm{kDa}$ pine nut (Pinus koraiensis) meal protein, with an exploration of the relationship between their antioxidant activities and secondary structure," Food Chemistry, vol. 219, pp. 311-320, 2017.

[5] S. Lin, X. Liu, B. Liu, and Y. Yu, "Optimization of pine nut (Pinus koraiensis) meal protein peptides on immunocompetence in innate and adaptive immunity response aspects," Food and Agricultural Immunology, vol. 28, no. 1, pp. 109-120, 2017.

[6] R. Jiao, Y. Liu, H. Gao, J. Xiao, and K. F. So, "The anti-oxidant and antitumor properties of plant polysaccharides," The American Journal of Chinese Medicine, vol. 44, no. 3, pp. 463-488, 2016.

[7] S. Sajadimajd, G. Bahrami, M. Daglia, S. M. Nabavi, R. Naseri, and M. H. Farzaei, "Plant-derived supplementary carbohydrates, polysaccharides and oligosaccharides in management of diabetes mellitus: a comprehensive review," Food Reviews International, vol. 35, no. 6, pp. 563-586, 2019.

[8] H. Qu, X. Gao, Z.-Y. Wang, and J.-J. Yi, "Comparative study on hepatoprotection of pine nut (Pinus koraiensis Sieb. et Zucc.) polysaccharide against different types of chemicalinduced liver injury models in vivo," International Journal of Biological Macromolecules, vol. 155, pp. 1050-1059, 2020.

[9] H. Qu, X. Gao, H.-T. Zhao, Z.-Y. Wang, and J.-J. Yi, "Structural characterization and in vitro hepatoprotective activity of polysaccharide from pine nut (Pinus koraiensis Sieb. et Zucc.)," Carbohydrate Polymers, vol. 223, p. 115056, 2019.

[10] X. Zhu, Y. Mang, F. Shen, J. Xie, and W. Su, "Homogenate extraction of gardenia yellow pigment from Gardenia Jasminoides Ellis fruit using response surface methodology," Journal of Food Science and Technology, vol. 51, no. 8, pp. 1575-1581, 2014.

[11] W.-G. Shi, Y.-G. Zu, C.-J. Zhao, and L. Yang, "Homogenate extraction technology of camptothecine and hydroxycamptothecin from Camptotheca acuminata leaves," Journal of Forestry Research, vol. 20, no. 2, pp. 168-170, 2009.

[12] T. Liu, C. Ma, L. Yang et al., "Optimization of shikonin homogenate extraction from Arnebia euchroma using response surface methodology," Molecules, vol. 18, no. 1, pp. 466-481, 2013.

[13] L. Ke and H. Chen, "Homogenate extraction of crude polysaccharides from Lentinus edodes and evaluation of the antioxidant activity," Food Science and Technology, vol. 36, no. 3, pp. 533-539, 2016.

[14] S. Alban, A. Schauerte, and G. Franz, "Anticoagulant sulfated polysaccharides: Part I. Synthesis and structure-activity relationships of new pullulan sulfates," Carbohydrate Polymers, vol. 47, no. 3, pp. 267-276, 2002.

[15] M. Dubois, K. A. Gilles, J. K. Hamilton, P. A. Rebers, and F. Smith, "Colorimetric method for determination of sugars and related substances," Analytical Chemistry, vol. 28, no. 3, pp. 350-356, 1956.

[16] M. M. Bradford, "A rapid and sensitive method for the quantitation of microgram quantities of protein utilizing the principle of protein-dye binding," Analytical Biochemistry, vol. 72, no. 1-2, pp. 248-254, 1976.

[17] A. A. Karaçelik, M. Küçük, Z. İskefiyeli et al., "Antioxidant components of Viburnum opulus L. determined by on-line HPLC-UV-ABTS radical scavenging and LC-UV-ESI-MS methods," Food Chemistry, vol. 175, pp. 106-114, 2015.

[18] K. M. Kalili, S. De Smet, T. Van Hoeylandt, F. Lynen, and A. de Villiers, "Comprehensive two-dimensional liquid chromatography coupled to the ABTS radical scavenging assay: a powerful method for the analysis of phenolic antioxidants," Analytical and Bioanalytical Chemistry, vol. 406, no. 17, pp. 4233-4242, 2014.

[19] C. Chen, L.-J. You, A. M. Abbasi, X. Fu, and R. H. Liu, "Optimization for ultrasound extraction of polysaccharides from mulberry fruits with antioxidant and hyperglycemic activity in vitro," Carbohydrate Polymers, vol. 130, pp. 122-132, 2015.

[20] Y. Xu, F. Cai, Z. Yu et al., "Optimisation of pressurised water extraction of polysaccharides from blackcurrant and its antioxidant activity," Food Chemistry, vol. 194, pp. 650-658, 2016.

[21] Z. Wu, M. Zhang, M. Xie et al., "Extraction, characterization and antioxidant activity of mycelial polysaccharides from Paecilomyces hepiali HN1," Carbohydrate Polymers, vol. 137, pp. 541-548, 2016.

[22] R. Mohammadi, M. A. Mohammadifar, A. M. Mortazavian, M. Rouhi, J. B. Ghasemi, and Z. Delshadian, "Extraction optimization of pepsin-soluble collagen from eggshell membrane by response surface methodology (RSM)," Food Chemistry, vol. 190, pp. 186-193, 2016.

[23] D. Wu, W. H. Min, J. S. Liu et al., "Functional properties of the protein isolate and major fractions of pine nut proteins prepared from the Changbai Mountain in China," Advanced Materials Research, vol. 881-883, pp. 766-775, 2014.

[24] Y.-C. Cheung, K.-C. Siu, Y.-S. Liu, and J.-Y. Wu, "Molecular properties and antioxidant activities of polysaccharide-protein complexes from selected mushrooms by ultrasoundassisted extraction," Process Biochemistry, vol. 47, no. 5, pp. 892-895, 2012.

[25] C. Li, H. Xue, Z. Chen, Q. Ding, and X. Wang, "Comparative studies on the physicochemical properties of peanut protein isolate-polysaccharide conjugates prepared by ultrasonic treatment or classical heating," Food Research International, vol. 57, pp. 1-7, 2014.

[26] J.-S. Jeon, H. G. Kim, B. H. Um, and C. Y. Kim, "Rapid detection of antioxidant flavonoids in azalea (Rhododendron mucronulatum) flowers using on-line HPLC-ABTS ${ }^{+}$system and preparative isolation of three flavonoids by centrifugal partition chromatography," Separation Science and Technology, vol. 46, no. 3, pp. 518-524, 2011.

[27] H. J. Lee, C.-H. Pan, E.-S. Kim, and C. Y. Kim, "Online high performance liquid chromatography (HPLC)-ABTS ${ }^{+}$based assay and HPLC-electrospray ionization mass spectrometry analysis of antioxidant phenolic compounds in Salsola komarovii," Journal of the Korean Society for Applied Biological Chemistry, vol. 55, no. 2, pp. 317-321, 2012.

[28] N. Peasura, N. Laohakunjit, O. Kerdchoechuen, and S. Wanlapa, "Characteristics and antioxidant of Ulva intestinalis sulphated polysaccharides extracted with different solvents," International Journal of Biological Macromolecules, vol. 81, pp. 912-919, 2015.

[29] X.-F. Cao, T. Yuan, S. Sun, and R.-C. Sun, "Isolation and characterization of soluble polysaccharides from Calamagrostis angustifolia Kom," BioResources, vol. 6, no. 3, pp. 2896-2911, 2011.

[30] R.-B. Xu, X. Yang, J. Wang et al., "Chemical composition and antioxidant activities of three polysaccharide fractions from pine cones," International Journal of Molecular Sciences, vol. 13, no. 12, pp. 14262-14277, 2012.

[31] M. Carbonaro and A. Nucara, "Secondary structure of food proteins by Fourier transform spectroscopy in the mid-infrared region," Amino Acids, vol. 38, no. 3, pp. 679-690, 2010.

[32] E. Goormaghtigh, J.-M. Ruysschaert, and V. Raussens, "Evaluation of the information content in infrared spectra for protein secondary structure determination," Biophysical Journal, vol. 90, no. 8, pp. 2946-2957, 2006. 